\title{
Innovative Prefabricated Composite Bridges
}

Peter Collin

Prof. Composite Structures

LTU/Scandiaconsult

Luleå, Sweden

Peter Collin, born 1960 , presented his $\mathrm{PhD}$ thesis 1992 , concerning the stability of steel frames. He has since been working with design and development of steel- and composite bridges.

\author{
Anders Stoltz \\ Civil Engineer \\ Luleå Univ. of Technology \\ Luleå, Sweden \\ Anders Stoltz, born 1974, \\ received his civil engineering \\ degree 1999. He has since been \\ working with his $\mathrm{PhD}$ studies in \\ the area of prefabricated bridge \\ decks as well as shear buckling \\ of web plates.
}

\author{
Mikael Möller \\ PhD D Steel Structures \\ ÅF Processdesign \\ Helsingborg, Sweden
}

Mikael Möller, born 1965, presented his $\mathrm{PhD}$ thesis within the area of inelastic local buckling. He has since been working with non-linear FEanalysis of steel structures.

\section{Summary}

The competitiveness of composite bridges depends on several circumstances such as site conditions, local costs of material and staff and the contractor's experience. One major advantage compared to concrete bridges is that the steel girders can carry the weight of the formwork and the wet concrete. Another advantage is the savings in construction time, which saves some money for the contractor but even more so for the road users, a fact that usually is neglected when evaluating alternative bridge designs. A further step to improve the competitiveness of composite bridges is to prefabricate not only the steel girders, but also the concrete deck. In this paper a new concept with dry joints between the elements is described.

Keywords: Composite bridges, prefabricated decks, deck elements, full scale testing.

\section{Introduction}

Composite bridges have become a popular solution in many countries [1], [2].

The competitiveness of composite bridges depends on several circumstances such as site conditions, local costs of material and staff and the contractor's experience. One major advantage compared to concrete bridges is that the steel girders can carry the weight of the formwork and the wet concrete, which means that the need for temporary structures is reduced, as indicated in Figure 1 and 2.

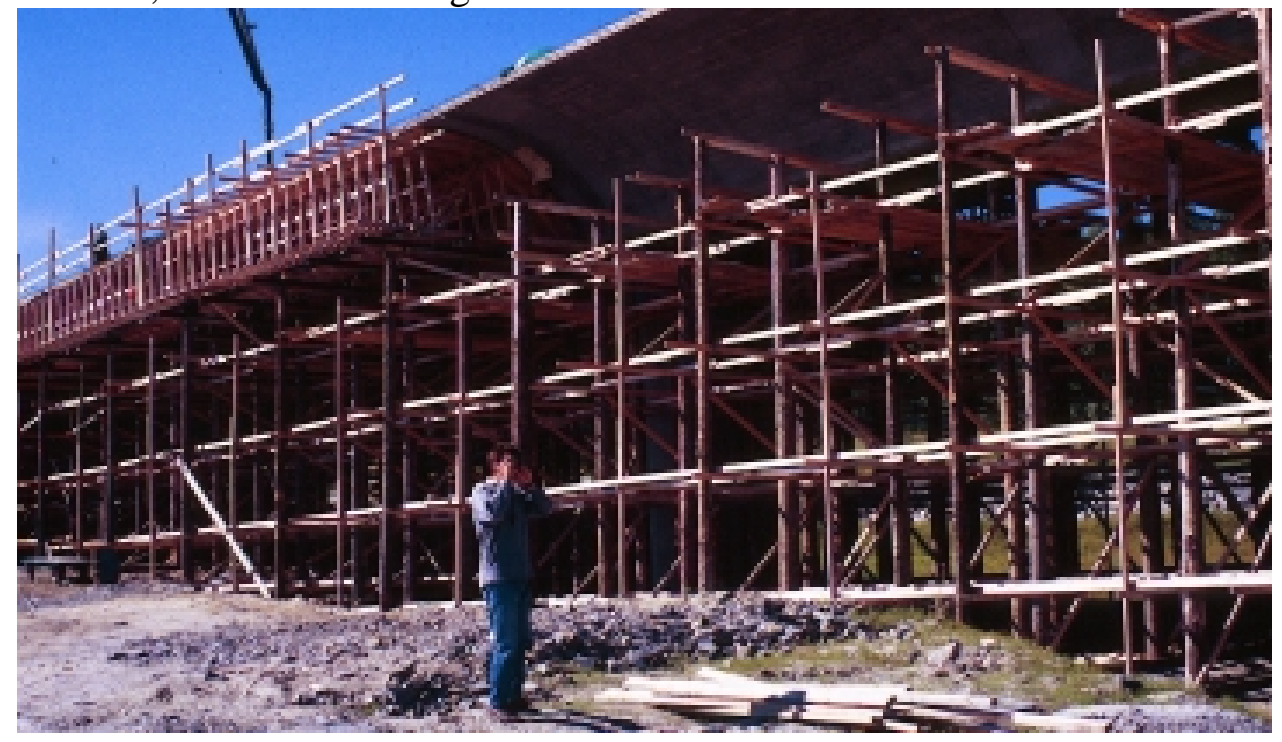


Fig. 1 Concrete bridge during construction.

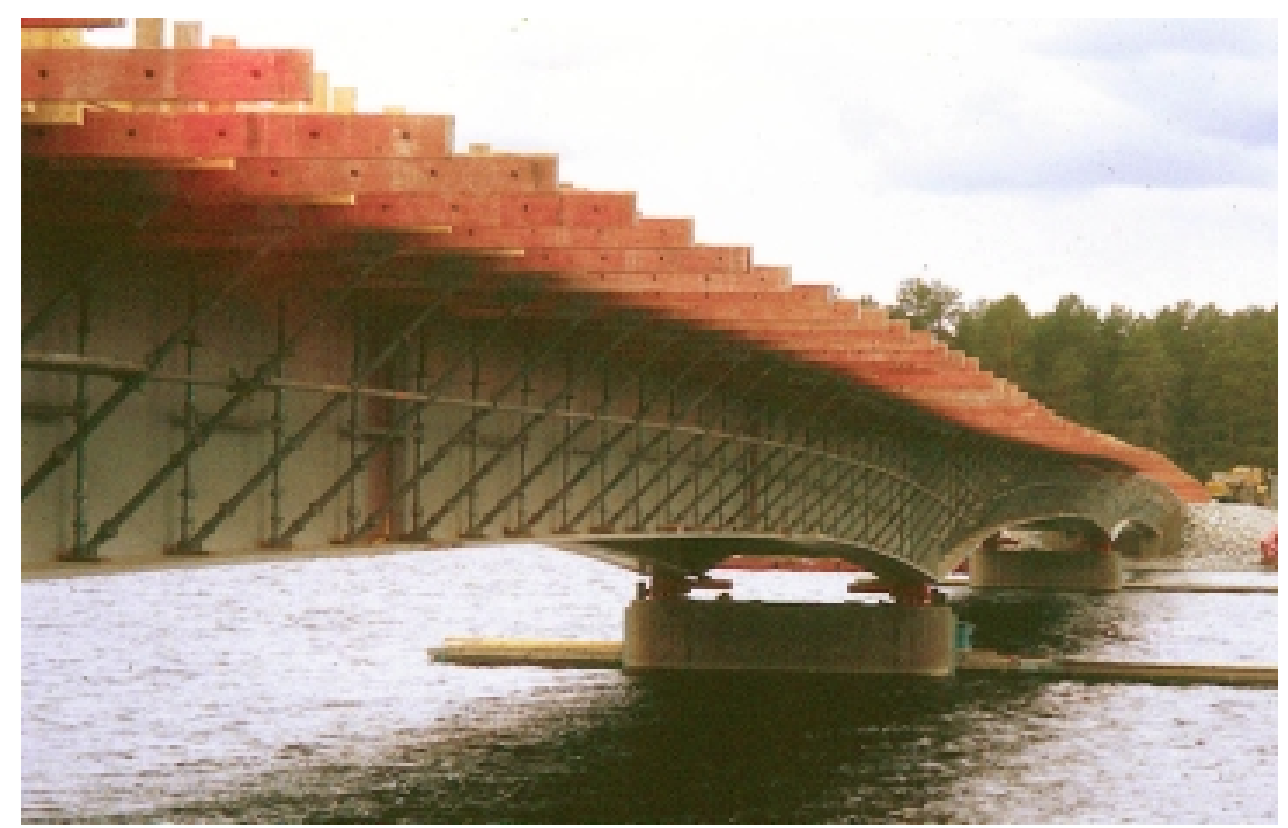

Fig. 2 Composite bridge during construction.

Another advantage is the savings in construction time, which saves some money for the contractor but even more so for the road users, a fact that usually is neglected when evaluating alternative bridge designs.

Traditionally, the concrete deck is cast on site, which means that the work with the formwork, reinforcement as well as the casting takes places outdoors. This work can be problematic and expensive during wintertime in countries with a cold climate.

A further step to improve the competitiveness of composite bridges is to prefabricate not only the steel girders, but also the concrete deck. The main advantages obtained by adopting this concept are listed below.

- A smaller amount of man-hours outdoors at the construction site.

- A shorter construction time.

- The deck elements are cast indoors, which is believed to result in improved quality.

- An improved working environment for the workers while erecting formwork, placing re-bars and casting concrete.

It is also clear that some problems need to be solved in connection with prefabricated deck slabs in order to make the concept cost efficient. This will be discussed in the following in addition to presenting some new solutions. 


\section{Various Solutions for Prefabricated Deck Elements}

Concrete elements acting compositely with steel girders have been used in many countries around the world, e.g. Germany, USA, Russia, France and Sweden. Two main questions that need to be answered are:

a) How shall the shear forces be transmitted between steel and concrete?

b) How shall the shear forces from e $g$ wheel loads be transmitted between the deck elements?
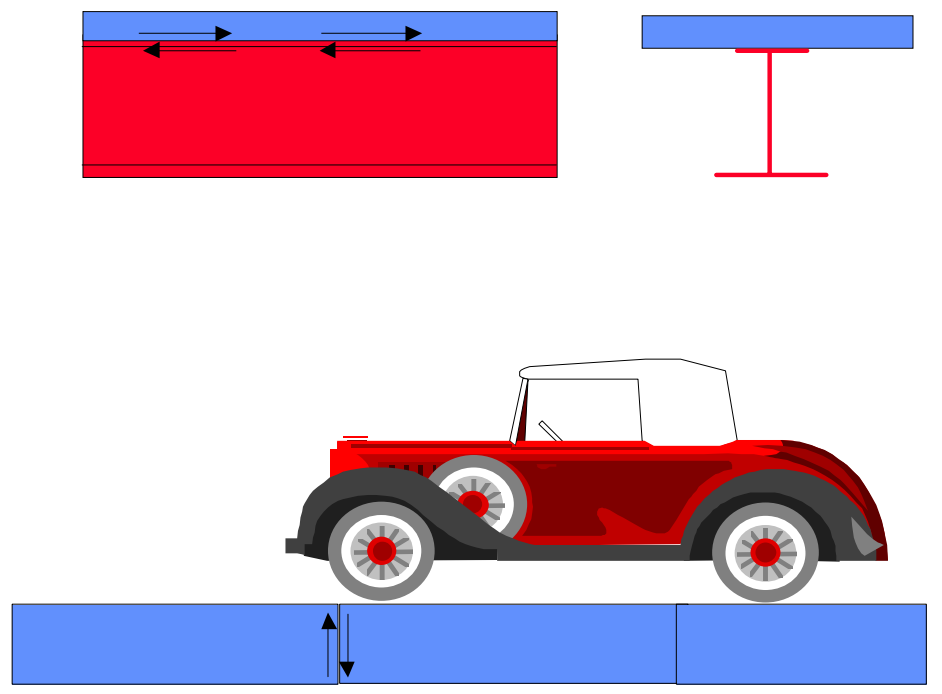

Fig.3 Illustration of shear forces between the steel girder and the concrete deck elements and between the deck elements, respectively.

In USA a solution has been developed, where the elements are connected to the steel girders by U-sections welded to the top flange [4]. The U-sections are placed in shear pockets in the elements, which are filled with epoxy concrete. The joint between the elements is a shear key, also filled with epoxy concrete. Compression struts in the concrete transfer the shear force, while the steel girders prevent the elements from separating.

Figure 4 shows a Swedish road bridge, where the elements are connected to the girders by means of headed studs. The elements are held together with eight post-stressed cables $\phi=16$ $\mathrm{mm}$.

The back walls and the side wings were also prefabricated. In order to minimise the thickness and thereby the weight of the back walls, a horizontal truss was used to transfer the earth pressure to the steel beams. 


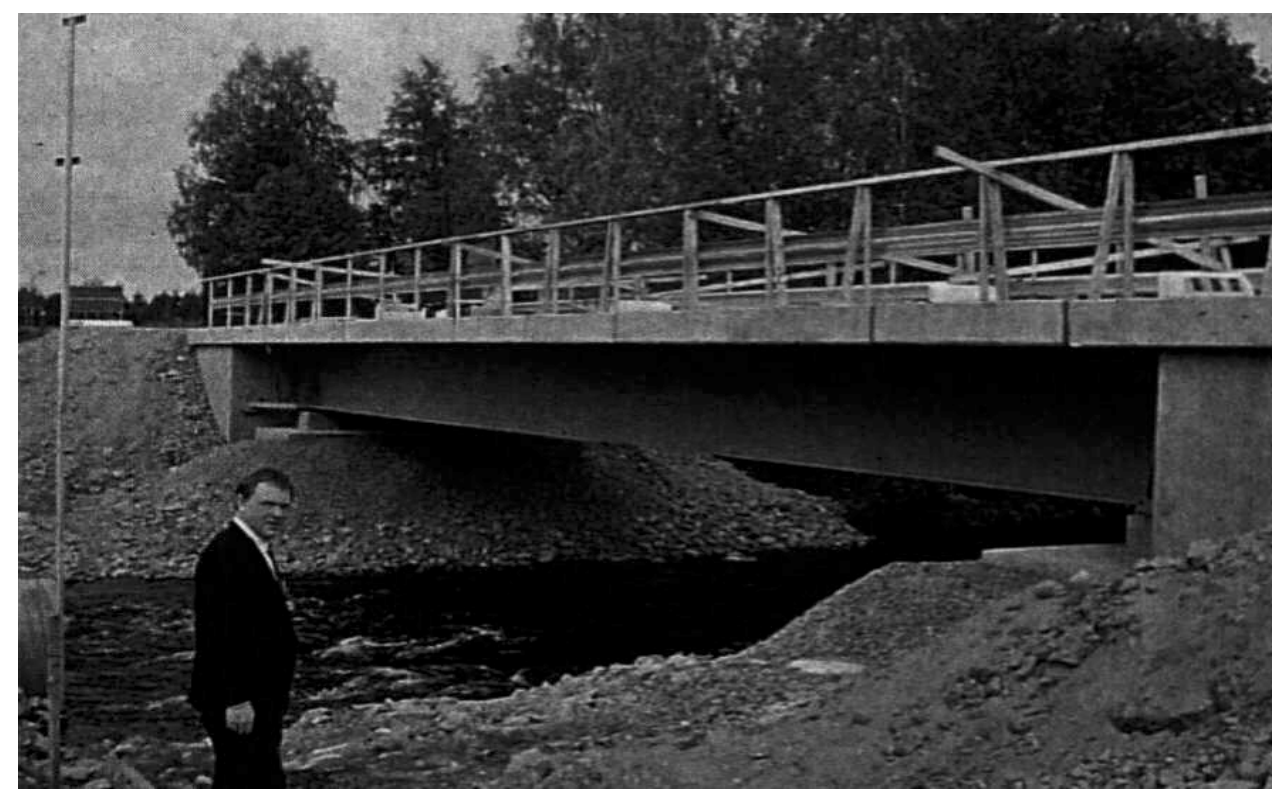

Fig. 4 Bridge over Flaxnan in Sweden. The shear connection between the deck elements and the girders was achieved by means of headed shear connectors in shear pockets. The $100 \mathrm{~mm}$ wide joints between the elements were grouted.

The concept described above was also used on a three span bridge, but turned out to be rather expensive. Therefore, it was natural to develop a new concept with reinforcement splices in $400 \mathrm{~mm}$ wide in situ cast joints. The required reinforcement area [3] in the joints was fulfilled by means of hairpin re-bars, $\phi=16 \mathrm{~mm}$. The elements featured the full width of the bridge and the length $1.8 \mathrm{~m}$.

The elements were fastened to the bridge girders by means of headed studs fitted in shear pockets in the elements. The quality of the drawings and the work carried out in the workshop was essential, since the shear connectors must fit between the longitudinal and transverse rebars of the deck elements. Figure 5 shows the erection of such a bridge.

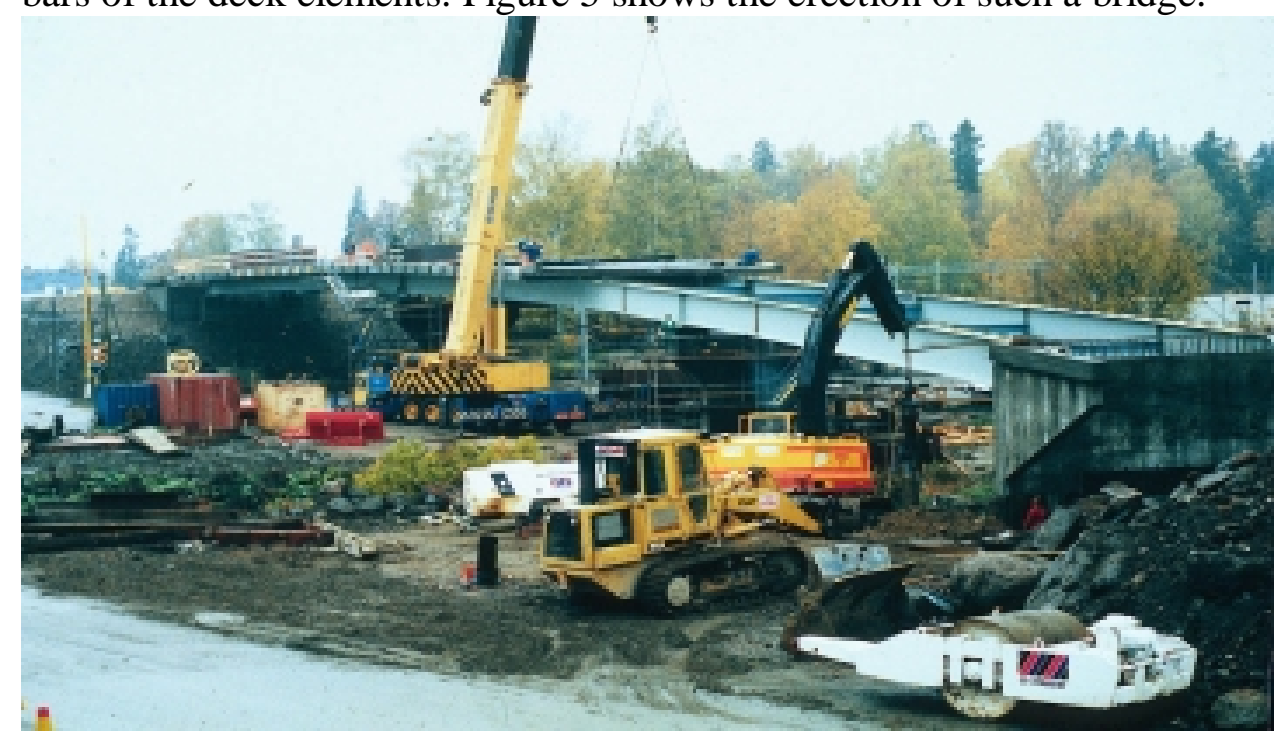

Fig. 5 Bridge over railway tracks In Örbyhus, Sweden with reinforcement splices in $400 \mathrm{~mm}$ wide in situ cast joints. Groups of shear connectors were placed on the top flange, in the rear end along a constant radius. 
In France, a similar concept was adopted using splices of straight bars in $640 \mathrm{~mm}$ wide joints [5]. One difference is the welding of the headed studs. In Sweden, they are welded to the top flange at the workshop, which means small tolerances with respect to the fitting between the shear connectors and the re-bars in the element shear pockets. In France, however, the shear connectors are welded after the elements are placed on the steel girders. So far, the concept with in situ cast joints has been used on approximately 15 bridges in Sweden, and more than 50 bridges in France.

\section{Deck Elements with dry Joints}

A research project is underway at Luleå University of Technology in collaboration with Strängbetong and Scandiaconsult. The project is funded by the Swedish Construction Industry's organisation for research and development, SBUF. Within the frames of this project, a new technology for dry joints between roadway elements has been developed. In the summer 2000 an old bridge was replaced across Rokån outside Piteå, using the new concept.

As the larger part of the timber traffic from the inner regions use the bridge across Rokån, the alternative would have been an expensive by-pass road. Instead, a bridge with prefabricated back walls, deck elements and foundation plinths, was chosen. Furthermore, the new bridge was erected temporarily next to the old bridge, which carried the traffic as usual. Finally the new bridge was launched sideways and placed on top of prefabricated supports.

7 p.m. - The road was closed.

10 p.m. - The old bridge was removed using two mobile cranes. The dismantling works continued until 6 p.m. the next day.

12 p.m. - Old back walls and side wings were removed. The ground behind the abutments was excavated. New gravel fill was placed to the correct level.

9 a.m. - The prefab plinths were placed on the new gravel bed.

9 a.m. - The lifting contractor temporarily placed the new bridge on launching girders, which took 4 hours. The sideways launching took only 10 minutes.

6 p.m. - Installation of bearings and filling behind the back walls.

1 a.m. - The bridge was opened to traffic. 


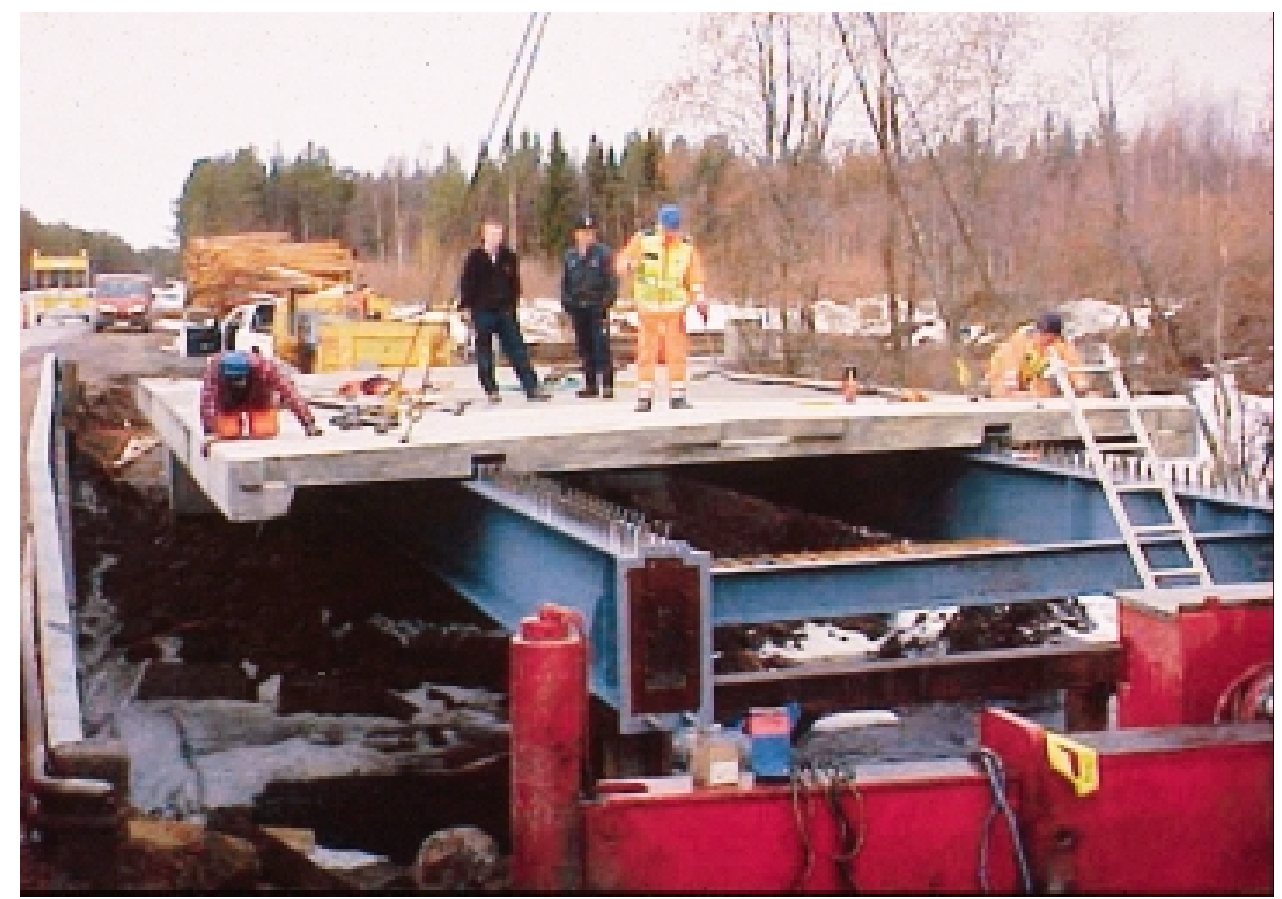

Fig. 6 Two more elements to go.

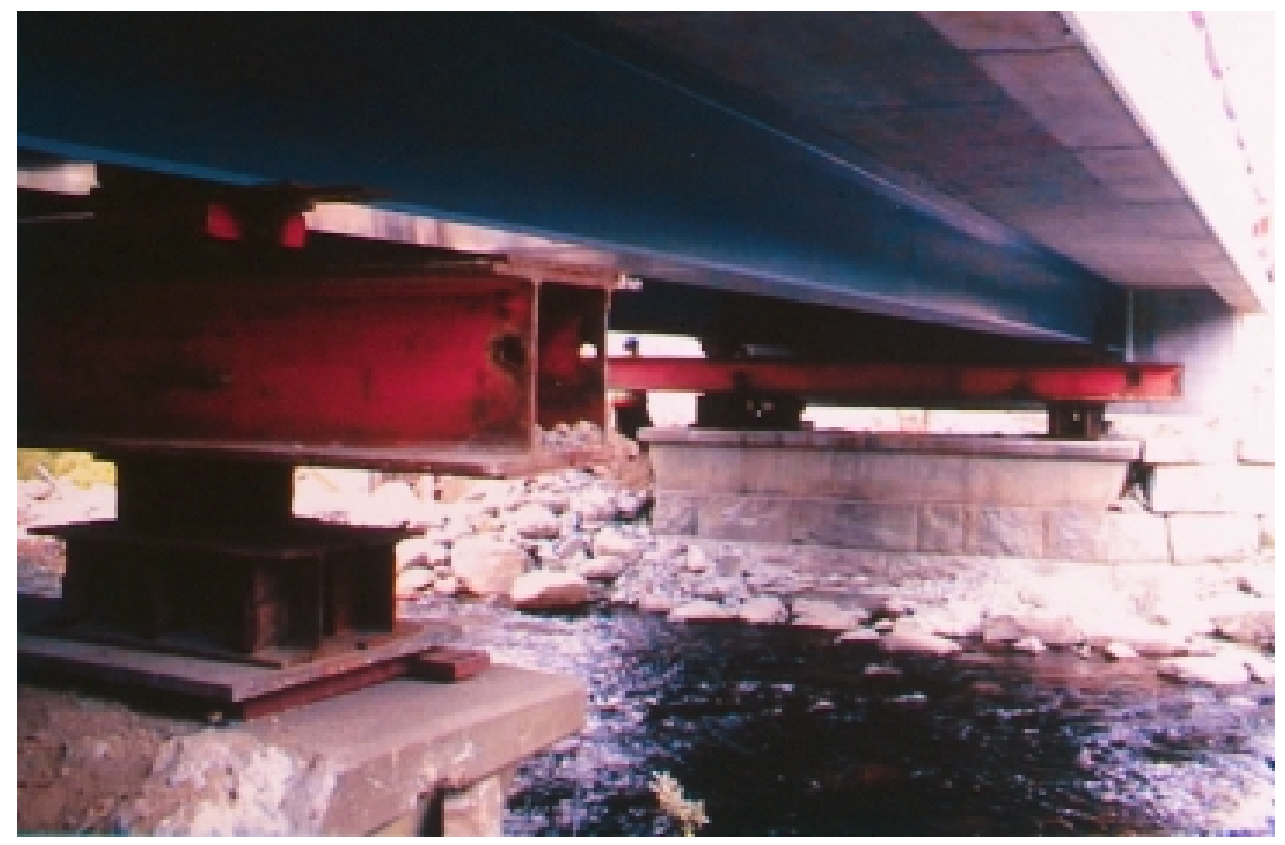

Fig. 7 Bridge across Rokån following the sideways launch. 


\section{Laboratory Testing}

The aim of the test was to simulate the behaviour of a composite girder with open joints in the concrete element deck when hogging bending moment is applied. The steel beams were HEA 900, S460 and the concrete was classified as C55. Shear connectors $22 \times 100 \mathrm{~mm}$ were placed in a channel in the concrete slab. The scale of the test specimen was approximately 2:3. Two hydraulic jacks at the cantilevering end of the composite girder applied the primary load. The joint opening, the displacement between steel and concrete was measured in a number of points, as well as the deflection of the girder.

Several tests were performed on the specimen. The first part was a test of the resistance to fatigue for the overlapping concrete tongues. A working load, with a frequency of $2 \mathrm{~Hz}$ and 1 million load cycles was applied at the joint over the midspan.

In the second part of the test a pulsating load was applied at the cantilevering end of the specimen in order to check the resistance to fatigue for the headed shear studs. The load was applied with a frequency of $1.5 \mathrm{~Hz}$ and 1 million load cycles. A final test to investigate if the overlapping concrete tongues had suffered from fatigue was also performed by a static load test. The joint at the midspan was tested and compered with one of the other joints that have not been subjected to fatigue. The test set-up can be seen in Figure 8.
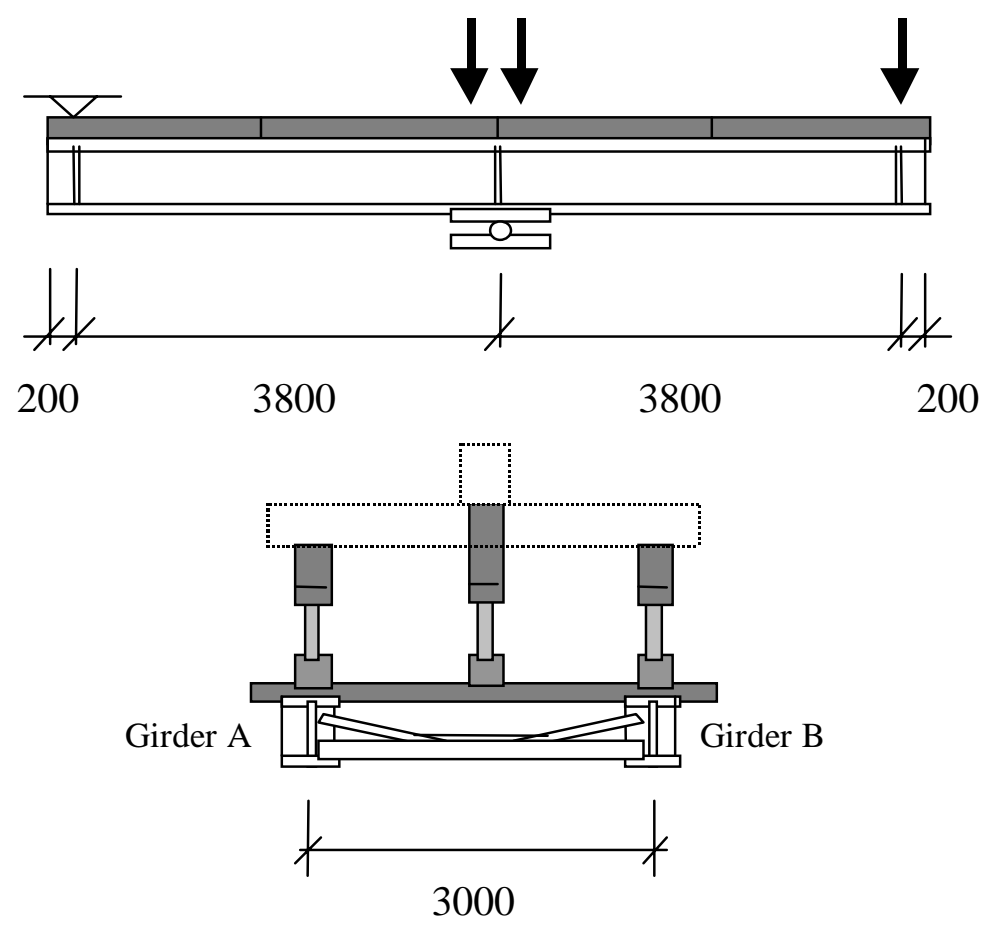

Fig. 8 Test setup with two hydraulic jacks over the internal support, and one hydraulic jack over each girder at the cantilevering end of the test specimen.

In the part of the test of the resistance to fatigue of the over lapping concrete tongues two hydraulic jacks, each with a capacity of $270 \mathrm{kN}$, were used. They were located at each side of the joint over mid support. The jacks applied the load with a phase shift of $180^{\circ}$ in order to simulate a passing wheel. In order to simulate the worst case, a static load of $250 \mathrm{kN}$ was 
applied at the cantilevering end of the test specimen. This applied global moment represents the effect of traffic load on the bridge.

The wheel loads were transferred into the specimen by a steel plate of 200x200x50 mm. The size of the plate is less than recommended according to EC 1-3 (400x400). The reason for using a smaller plate was to concentrate the load to the over lapping concrete tongues. The steel plates were embedded in high strength gypsum mortar. For the test set-up for the fatigue test of the shear connectors the jacks were moved from mid support to the cantilevering end of the test specimen. The jacks were now synchronised and applied a load of $245 \mathrm{kN}$. The applied load resulted, according to a FE-analysis, in a shear force of $44 \mathrm{kN}$ on the shear connectors in the region closest to mid support.

Due to the fact that the shear connectors were not possible to inspect, acoustic emission was used to detect crack propagation. Measuring devices were applied with a displacement of 500 $\mathrm{mm}$ from the edge of the girder, on one of the two girders composite flange. Two devices were used on each end of the girder; they were applied in the transversal direction in the middle between the edge of the flange and the end of the radius.

The test of the overlapping concrete tongues indicated good results when subjected to fatigue load. The horizontal opening of the joint at the midspan remains almost constant through out the test of 1 million load cycles. The joint over mid support had an opening of $1.06 \mathrm{~mm}$ due to the fact that the specimen was subjected to a global negative moment. The increase of the horizontal opening of the joint at the midspan due to the fatigue load was $0.073 \mathrm{~mm}$. The average initial opening of the joint at the midspan was $0.15 \mathrm{~mm}$. The total opening in the horizontal direction caused by the loads was $1.13 \mathrm{~mm}$. For the other two joints the horizontal deflection was constant through out the test.

The relative vertical deflection between the two concrete slabs on each side of the joint at the midspan was at the beginning $1.24 \mathrm{~mm}$ and at the end of the test, after 1 million load cycles, $1.42 \mathrm{~mm}$. The vertical movement increased with $0.18 \mathrm{~mm}$ during the test. There were no indications that the concrete tongues had suffered from fatigue during the test. No visible cracks of the concrete tongues or dramatic change of behaviour was found through out the test. After the fatigue test a test was performed to check the resistance to static load of the concrete tongues. The joint at the midspan, that have been subjected to fatigue load, was tested as well as one of the other joints that had not been subjected to fatigue load as a reference. The results confirm that the joint at the midspan had not suffered from fatigue. The maximum static load was about the same for the two tested joints. For the joint at the midspan the maximum load was $1046 \mathrm{kN}$ and for the other joint $1001 \mathrm{kN}$.

For this part of the test the horizontal opening of the joints as well as the vertical deflection of the cantilevering end of the specimen was constant during the test. The vertical movement of the concrete slabs was measured at the midspan from 100,000 to 1 million load cycles. Due to technical limitations it was not possible to apply the LVDT-gauge until after 100,000 load cycles. The vertical movement increases with $0.05 \mathrm{~mm}$. Due to technical limitations it was only possible to measure the slip between one of the concrete slab and the steel girders.

Unfortunately all shear connectors that failed were located in the other slab. Therefor it was not possible to detect any increase in the slip between the slab and the steel girders. The measured slip remained constant through out the test on a level of $0.13 \mathrm{~mm}$ on one side of the specimen and about $0.17 \mathrm{~mm}$ on the other side. 
The results from the measuring of acoustic emission, $\mathrm{AE}$, and the measuring of the strain caused by the bending of the headed studs indicated that at least three, but probably four, headed studs had failed due to fatigue. Failure for three headed studs was confirmed visually after the end of the test.

The conclusions that can be drawn from the tests are the following:

- The overlapping concrete tongues can clearly resist the fatigue load as well as the static load according to EC 1-3.

- For a continuous bridge the joint tends to open over intermediate supports. The total horizontal opening during the test was $1.1 \mathrm{~mm}$. The total vertical movement of the concrete slabs relatively each other, caused by a passing wheel, over an intermediate support was $1.4 \mathrm{~mm}$ during the test. This movement of the joint could be a cause problem for the waterproofing and surfacing why this has to be investigated.

- Even if the elements in tension near the support will not be included in the design calculations, it is strongly recommended that they should be properly connected to the steel girders. The connection should be as strong as possible without exceeding the tensile strength of the concrete. The force on the connectors will vary with the traffic load and may cause fatigue failure. The laboratory test with 1 million load cycles caused three studs, but probably four, to fail from fatigue. The calculated force on the studs of $44 \mathrm{kN}$ is high compared to the expected resistance to fatigue according to EC 4-2 for 1 million cycles.

- Acoustic emission was used and it was possible to detect the propagation of cracks of the headed shear connectors.

\section{Full Scale Testing of Bridge over Rokån}

A bridge was built in 2000 as described in Section 3.4 months after completion, tests were performed on the bridge [7]. The bridge was loaded with a truck while strains as well as deflection were measured. The wheel loads from the truck are visualised in Figure 9. Note that this is much less than the design load and the purpose of the test was only to check the elastic behaviour e. g. how well the element slab acted compositely with the steel beams. The strains were measured in both flanges at four points along one of the two bridge girders. Deflection was measured at midspan.

The truck was placed in three different locations along each steel girder. This was done to see how much of the load each beam carries. In a traditional calculation, it is assumed that one beam takes the entire vehicle load if it is positioned exactly over that beam. In reality the two beams will share the load due to torsional stiffness, warping stiffness as well as restraint from the back wall.

The strains that were measured were transformed to stresses using Hooke's law and separated into one bending part and one torsion/warping part. The bending and warping stresses were also calculated by means of FE-analysis, using shell elements with four nodes each. A 
comparison between calculated stresses and measured stresses (total direct stress) for the lower flange with the truck positioned at mid span is shown in Table 1.

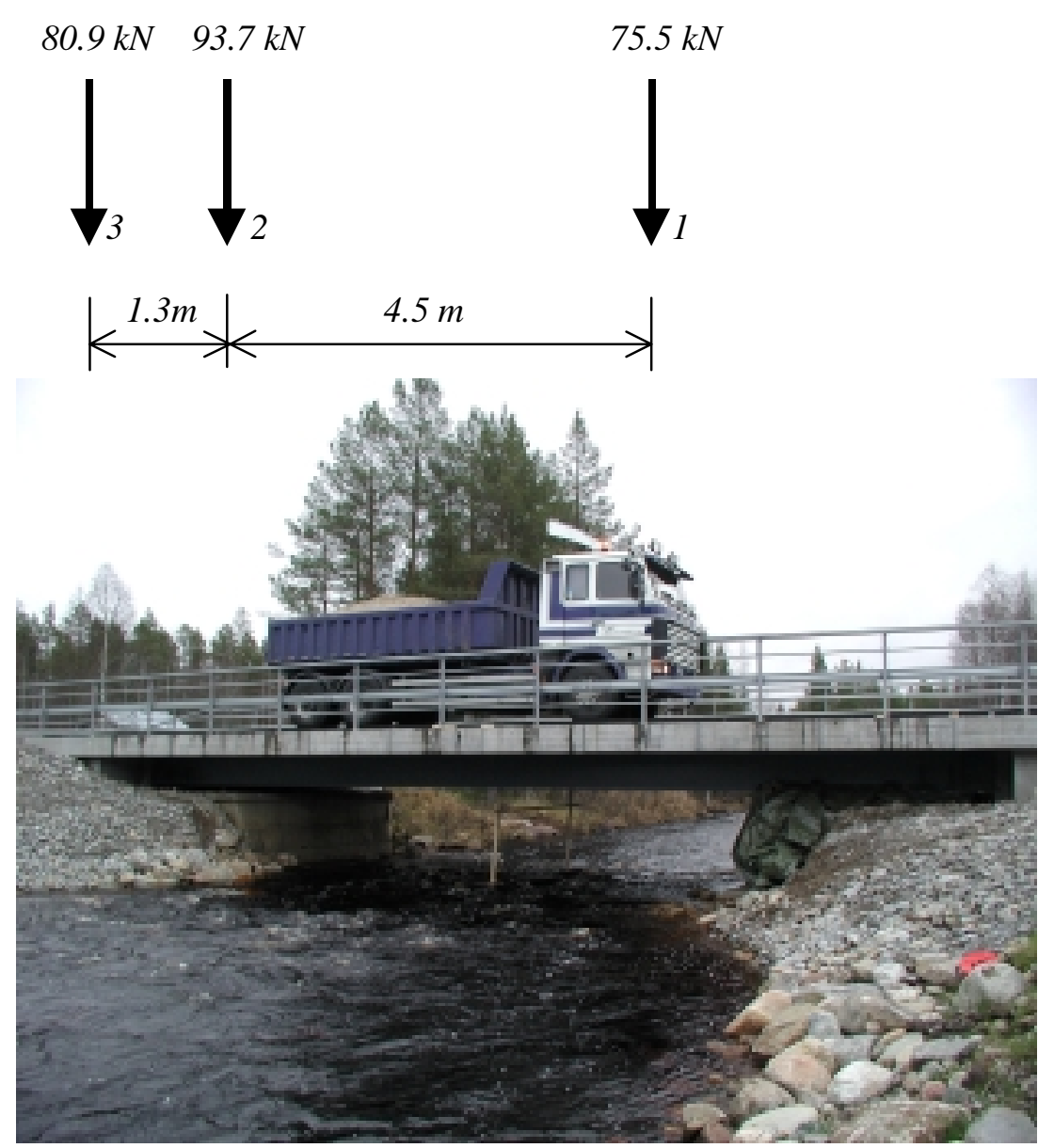

Fig. 9 Loads on the bridge during testing.

Table 1. Comparison between calculated and measured stresses and deflection for bottom flange at mid span. In the calculations, the torsion and warping as well as the restraint from the back wall are taken into account. Here, $\delta_{1}$ and $\delta_{2}$ denote the midspan deflection for the left and right girder, respectively.

\begin{tabular}{|c|c|c|}
\hline$\sigma_{\text {lower }}[\mathbf{M p a}]$ & $\begin{array}{c}\text { FEM } \\
\text { Calculations } \\
28.3\end{array}$ & $\begin{array}{c}\text { Measured } \\
\text { values } \\
26.3\end{array}$ \\
\hline$\sigma_{\text {upper }}[\mathbf{M p a}]$ & 7.6 & 7.6 \\
\hline$\Sigma \sigma[\mathrm{MPa}]$ & 35.9 & 33.9 \\
\hline$f[-]$ & 0.79 & 0.78 \\
\hline$\delta_{1}[\mathrm{~mm}]$ & 4.6 & 4.5 \\
\hline
\end{tabular}




\begin{tabular}{||c|c||c||}
\cline { 2 - 3 }$\delta_{2}[\mathrm{~mm}]$ & 1.4 & 1.8 \\
\hline$\Sigma \delta[\mathrm{mm}]$ & 6.0 & 6.3 \\
\hline
\end{tabular}

The test showed that around two thirds of the concrete slab was effective as part of the composite beam. The reason why the whole slab is not active is the small gaps between elements as discussed in Chapter 4. In the Ultimate Limit State, the load effect from traffic will be approximately four times higher than during the tests. With higher load, the gaps will decrease and a larger part of the concrete slab will carry compressive forces.

The test results also showed that a considerable end moment exists that lowers the maximum moment by $30 \%$. It also showed that the retaining walls add torsional rigidity to the structure, which lowers the stresses in the girder carrying the heaviest load when a vehicle is eccentrically placed on the bridge.

\section{Conclusions}

Composite bridges are a well-established alternative to concrete bridges. The new concept for composite bridges with prefabricated decks described in this paper offers several advantages; faster erection time, higher quality, better working environment and a dry bridge deck surface.

Laboratory tests carried out on the elements indicate excellent abilities to withstand both static and fatigue loading. A pilot project in northern Sweden erected in June 2000 clearly showed that the concept works well on site. A full-scale test of that specific bridge demonstrated that the composite action between the steel girders and the concrete deck is excellent, although the joints between the match cast elements are not grouted.

\section{References}

[1] COLLIN P., "Some trends in Swedish Bridge Construction", International Conference on welded Structures, 2-3 September 1996, Budapest, Hungary, pp 163-172.

[2] COLLIN P. and JOHANSSON B., "Wettbewerbsfähige Brücken in Verbundbauweise", Stahlbau 68, 1999, Heft 11, pp 908-918.

[3] BRO94, Swedish Regulations for Bridges, Swedish National Road Administration, Borlänge, 1994(in Swedish).

[4] Precast slabs for composite bridge decking. United States Steel, November 1981. ADUSS 88-7958-01.

[5] Innovative Composite Design of Motorway Overbridges. Europrofil ARBED, Luxembourg.

[6] STOLTZ A., "Effektivare samverkansbroar", Licentiate Thesis 2001:141, Luleå University of Technology, 2001(in Swedish).

[7] COLLIN P. and MÖLLER M., "Utvärdering av belastningsprov-Bro över Rokån”, Technical Report 01:01, Luleå University of Technology, Division of Steel Structures, 2001(in Swedish). 